\title{
Yeast heterochromatin is a dynamic structure that requires silencers continuously
}

\author{
Tzu-Hao Cheng and Marc R. Gartenberg ${ }^{1,2}$ \\ Department of Pharmacology, University of Medicine and Dentistry of New Jersey, Robert Wood Johnson Medical School, \\ Piscataway, New Jersey 08854 USA
}

\begin{abstract}
Transcriptional silencing of the $H M$ loci in yeast requires cis-acting elements, termed silencers, that function during S-phase passage to establish the silent state. To study the role of the regulatory elements in maintenance of repression, site-specific recombination was used to uncouple preassembled silent chromatin fragments from silencers. DNA rings excised from $H M R$ were initially silent but ultimately reactivated, even in $G_{1^{-}}$or $G_{2} / M$-arrested cells. In contrast, DNA rings bearing $H M L$-derived sequence were stably repressed due to the presence of a protosilencing element. These data show that silencers (or protosilencers) are required continuously for maintenance of silent chromatin. Reactivation of unstably repressed rings was blocked by overexpression of silencing proteins Sir3p and Sir4p, and chromatin immunoprecipitation studies showed that overexpressed Sir3p was incorporated into silent chromatin. Importantly, the protein was incorporated even when expressed outside of $S$ phase, during $G_{1}$ arrest. That silencing factors can associate with and stabilize preassembled silent chromatin in non-S-phase cells demonstrates that heterochromatin in yeast is dynamic.
\end{abstract}

[Key Words: Transcriptional repression; silencers; Saccharomyces cerevisiae; mating-type locus; Sir proteins; heterochromatin]

Received December 6, 1999; revised version accepted January 7, 2000.

Large regions of eukaryotic chromosomes are transcriptionally quiescent due to the packaging of DNA in repressive chromatin structures that are heritably propagated from one generation to the next. Heterochromatin, a constitutively condensed form of inactive chromatin, represents a primary example (Elgin 1996). Although heterochromatic regions are generally gene poor, heritable inactivation of either one of the two X chromosomes in female mammals involves formation of heterochromatin over the entire chromosome (Lee and Jaenisch 1997). In addition, chromosomal translocations that reposition active euchromatic genes near heterochromatin frequently result in a metastable form of repression that persists in subsequent generations.

Heritable inactivation of chromosomal domains in yeast Saccharomyces is typified by the HM loci (HMR and $H M L)$; in which endogenous copies of the matingtype genes are normally stored in a transcriptionally repressed state (Herskowitz et al. 1991). Inactivation of either $H M R$ or $H M L$ involves a pair of flanking cis-acting regulatory sequences, referred to as the $E$ and $I$ silencers, that bind Raplp, Abflp, and the replication origin recognition complex (ORC) in various combinations (Loo and

\footnotetext{
${ }^{1}$ Member, The Cancer Institute of New Jersey.

${ }^{2}$ Corresponding author.

E-MAIL gartenbe@UMDNJ.edu; FAX (732) 235-4073.
}

Rine 1995). An additional factor, Sirlp, is localized to silencers via protein-protein interactions (Triolo and Sternglanz 1996). Together, silencer-bound proteins recruit other Sir factors, Sir2p, Sir3p, and Sir4p, which associate with one another and histones throughout the repressed domain (Moretti et al. 1994; Hecht et al. 1995, 1996; Moazed and Johnson 1996; Strahl-Bolsinger et al. 1997). The resulting chromatin form, termed silent chromatin, bears many structural similarities to heterochromatin of higher eukaryotes. Both are assembled with hypoacetylated histones (Braunstein et al. 1993), both involve ORC as a DNA-binding component (Bell et al. 1993; Huang et al. 1998), and both are refractory to an array of DNA modification enzymes (Singh and Klar 1992; Loo and Rine 1994; Wallrath and Elgin 1995). This generalized chromatin inaccessibility, termed silencing in yeast, accounts for the block to transcription of both native and heterologous genes (Brand et al. 1985; Schnell and Rine 1986), as well as the diminished capacity for DNA repair (Terleth et al. 1989). Although heterochromatic structures are commonly assumed to be more or less static and inert, recent evidence suggests that cell cycle-dependent fluctuations occur. During mitotic chromosome condensation, much of the mouse heterochromatin protein HP1 is displaced from chromosomes (Murzina et al. 1999) and the accessibility of silenced yeast telomeric regions is increased in $\mathrm{G}_{2} / \mathrm{M}$-arrested cells (Aparicio and Gottschling 1994). 
A prevailing model for silencing has emerged in which repression consists of both establishment and maintenance phases. Accordingly, the establishment phase is one in which silent chromatin is reformed on nascent daughter duplexes following DNA replication. The maintenance phase, on the other hand, is one that sustains the silent state between successive establishment events. These concepts were first introduced by Miller and Nasmyth (1984) who used a conditional sir3 allele to show that de novo establishment of the silent state occurred during S-phase passage exclusively. Subsequent genetic studies isolated mutations in SIR1, RAP1, and silencers that impaired establishment but not maintenance of silencing (Pillus and Rine 1989; Mahoney et al. 1991; Sussel et al. 1993). In such mutants genotypically identical cells displayed variegated silencing phenotypes: In some cells the HM loci were "off", whereas the loci were "on" in others. Switching between expression states occurred, albeit infrequently, indicating that the conditions that specify a particular state were reversible. The interpretation of this epigenetic behavior was that silencing could be maintained once established but that establishment in the mutants was an inefficient process. That all of these mutations were linked to silencers supported the notion that the elements were critical for establishment. Sir3p, on the other hand, was shown to be required continuously to maintain silencing; inactivation of the protein during any stage of the cell cycle led to immediate derepression (Miller and Nasmyth 1984). Therefore, Sir3p and other structural components that span the repressed domain (Sir2p and Sir4p) have come to be viewed as maintenance factors.

An unexpected role for silencers in maintenance of the silent state was first suggested by mutations in the ORC complex. Inactivation of conditional ORC subunits led to partial derepression of $H M R \mathbf{a}$ in $\mathrm{G}_{2} / \mathrm{M}$-arrested cells, indicating that the silencer binding complex was required at times other than S phase for silencing (Fox et al. 1995). Complimentary data were obtained from more re- cent experiments in which preassembled silent chromatin domains were uncoupled from silencers by an inducible site-specific recombinase. Using this strategy, Holmes and Broach (1996) showed that removal of silencers from the chromosomal $H M L \alpha$ led to reactivation within a single cell cycle. In reciprocal studies by the Broach laboratory and our own, focus was placed on extrachromosomal rings that were excised from silent loci. Though initially silent, the nonreplicating rings were also not able to maintain silencing in the absence of silencers (Bi and Broach 1997; Cheng et al. 1998). In the case of $H M L$ derived rings, cell cycle progression between $G_{1}$ and $G_{2}$ was required for reactivation (Bi and Broach 1997). A general view that emerges from this work is that derepression in the absence of silencers is triggered by a cell cycle specific event.

Here we capitalize on the DNA ring excision approach to investigate the relationship between silencers and silent chromatin stability. We show that the elements function continuously in cis to maintain silent chromatin, even in $\mathrm{G}_{1}$ - and $\mathrm{G}_{2} / \mathrm{M}$-arrested cells. Furthermore, we show that silencing proteins can be recruited to silent chromatin during $\mathrm{G}_{1}$ arrest. We propose that silencers act continuously throughout the cell cycle for this purpose. The experiments provide a unique and informative glimpse at the unexpected dynamic nature of silent chromatin.

\section{Results}

\section{Maintenance of silencing at HMRa requires silencers}

Previously, we found that DNA rings excised from $H M R$ did not maintain silencing in logarithmically growing cells if the rings lacked silencers. Specifically, a ringborne copy of the a1 gene was initially not expressed, yet it became fully activated within one to two doublings in cell density following excision. To determine whether reactivation required cell cycle progression, we mea-

Table 1. Yeast strains

\begin{tabular}{|c|c|}
\hline W303-1A & MATa $H M L \alpha H M R \mathbf{a}$ ade2-1 can1-100 his3-11,15 leu2-3,112 trp1-1 ura3-1 \\
\hline THC23 & W303-1A hmr::rHMRa $\Delta$ sir3::HIS3 \\
\hline THC37 & W303-1A $\Delta$ mat::URA3 hmr::rHMRa + EI \\
\hline THC42 & W303-1A $\Delta$ mat::TRP1 hmr::rHMRa $\Delta$ bar1::hisG $\Delta$ lys2 $\Delta$ sir3::HIS3 \\
\hline THC43 & W303-1A $\Delta$ mat::TRP1 hmr::rHMRa $\Delta$ bar1::hisG $\Delta$ lys2 \\
\hline THC51 & 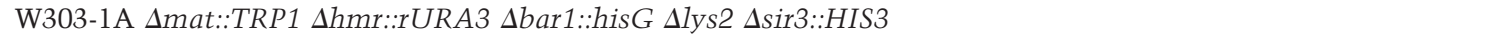 \\
\hline THC57 & W303-1A $\Delta$ mat::TRP1 hmr::rHMRa ura3-1::GAL10P-SIR3::URA3 $\Delta$ bar1::hisG $\Delta$ lys2 \\
\hline THC59 & 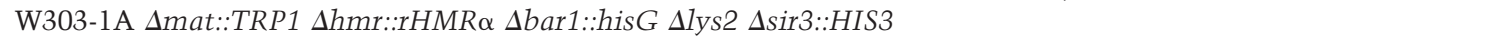 \\
\hline THC62 & W303-1A $\Delta$ mat::TRP1 $\Delta$ hmr::rHMR $\Delta$ bar1::hisG $\Delta l y s 2$ \\
\hline THC67 & 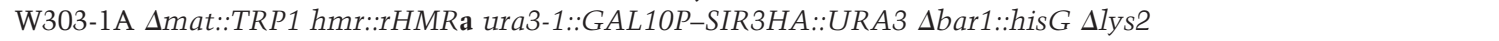 \\
\hline THC68 & 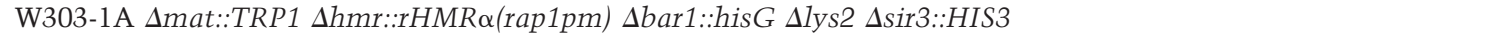 \\
\hline THC69 & 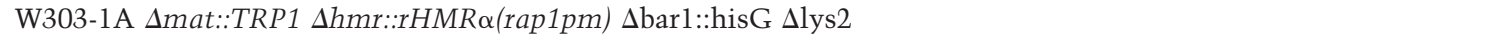 \\
\hline THC70 & W303-1A $\Delta$ mat::TRP1 hmr::rHMRa $\Delta$ hml::kanMX ura3-1::GAL10P-SIR3HA::URA3 $\Delta$ bar1::hisG $\Delta$ lys2 $\Delta$ sir3::HIS3 \\
\hline THC74 & W303-1A URA3 HML $\alpha:: U R A 3 P-A D E 2$ \\
\hline THC75 & 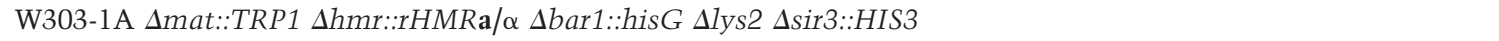 \\
\hline THC76 & W303-1A URA3 hml(rap1pm)::URA3P-ADE2 \\
\hline THC77 & W303-1A $\Delta$ mat::TRP1 $\Delta$ hmr::rHMRa/ $\Delta$ bar1::hisG $\Delta$ lys2 \\
\hline THC78 & W303-1A $\Delta$ mat::TRP1 hmr::rHMRa $\Delta$ hml::kanMX $\Delta$ bar1::hisG $\Delta$ lys2 $\Delta$ sir3::HIS3 \\
\hline THC79 & W303-1A $\Delta$ mat::URA3 hmr::rHMRa + EI $\Delta$ hml::kanMX $\Delta$ sir3::HIS3 \\
\hline
\end{tabular}


sured the persistence of silencing in rings in non-cycling cells. To this end, chromosomal fragments containing the a mating-type genes, either with or without silencers (Fig. 1), were excised from $H M R$ in cultures that had been treated with $\alpha$-factor mating pheromone. Greater than $98 \%$ of cells arrested at $G_{1}$ and remained there for the duration of the experiment, as confirmed by flow cytometry and a persistent unbudded shmoo morphology (data not shown). In the silencing-competent $\Delta$ mat strains used here, no a1 transcript was detected prior to recombination (Cheng et al. 1998). However, in a strain containing a conditional sir3 allele, fully derepressed a1 levels were observed within $60 \mathrm{~min}$ of a shift to nonpermissive conditions (data not shown). These preliminary tests indicated that a 1 gene expression could serve as a sensitive and rapid indicator of loss of silencing.

Ring formation was initiated by galactose-induced expression of the $\mathrm{R}$ recombinase, and 1 mRNA levels were measured by Northern analysis at timed intervals thereafter. In a ring that lacked silencers, no a 1 transcript was detected at the 60-min time point, indicating that the ring was initially repressed (Fig. 2A, lane 2). After 210 min, however, a1 mRNA began to accumulate, and by

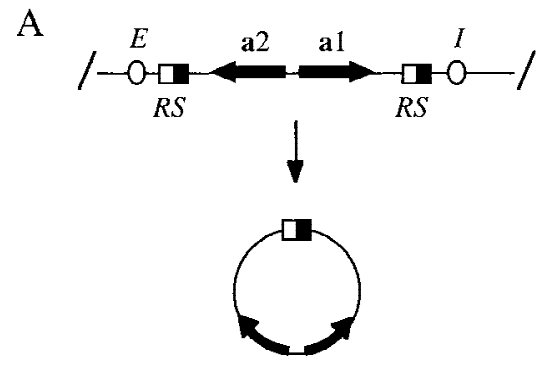

B

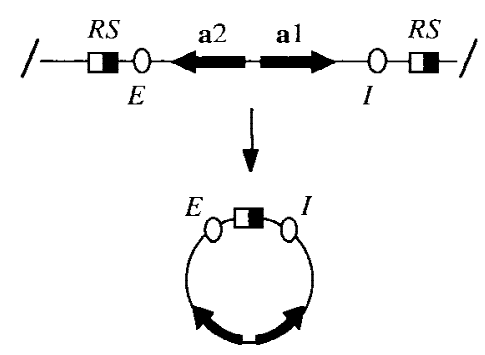

Figure 1. Excision of chromosomal fragments by site-specific recombination. $R S$ target sites (half-filled boxes) for the Zygosaccharomyces rouxii $\mathrm{R}$ recombinase (Matsuzaki et al. 1990) were built into the $H M R$ locus, either within the $E$ and $I$ silencers $(A)$, or just beyond the $E$ and $I$ silencers $(B)$ to produce rings that either lacked or contained the elements, respectively. In most laboratory strains, $H M R$ contains the a1 and a2 matingtype genes (HMRa), whereas $H M L$ contains the $\alpha 1$ and $\alpha 2$ mating-type pair $(H M L \alpha)$. A third mating-type locus, $M A T$, contains an active copy of either pair of mating-type genes. In the various experiments described herein, either a mating type sequences, $\alpha$ mating type sequences, or a composite of the two were positioned at $H M R$ for subsequent excision. All excision cassettes are named according to the rings they produce (e.g., locus hmr$: \because r H M R \mathbf{a}$ shown in $A$ produces ring rHMRa).
A
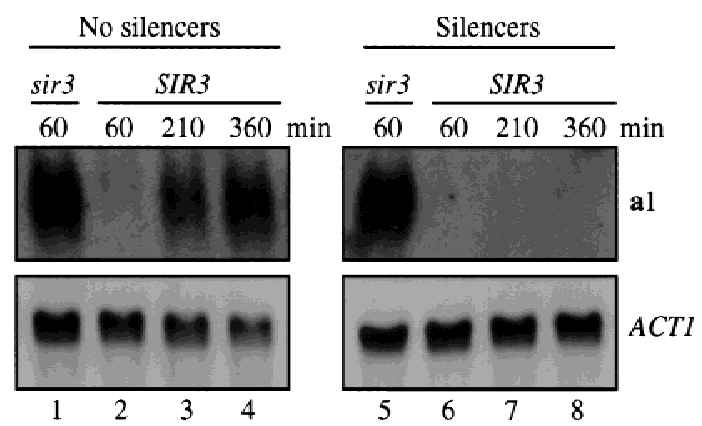

B

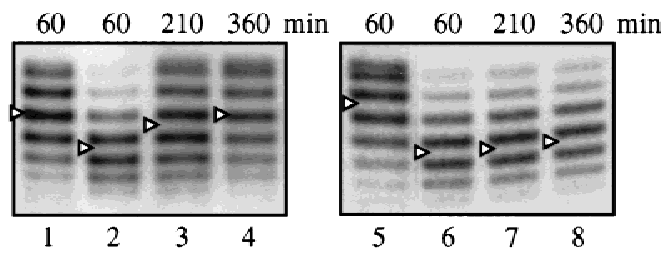

$\mathrm{C}$

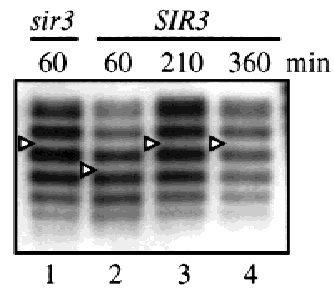

Figure 2. Maintenance of silencing requires silencers. DNA rings were excised from $H M R$ by induction of recombination in cell cycle-arrested cultures. Strains THC78 hmr::rHMRa $\Delta \mathrm{hml}$ ::kanMX $\Delta$ sir3::HIS3 (lane 1) and THC43 hmr::rHMRa (lanes 2-4) produced rings that lacked silencers. Strains THC79 hmr::rHMRa+EI $\Delta$ hml::kanMX $\Delta$ sir3::HIS3 (lane 5) and THC37 hmr::rHMRa+EI (lanes 6-8) produced rings that contained silencers. $H M L \alpha$ was deleted in the sir3 strains; otherwise, expression of the locus would have prevented arrest by $\alpha$-factor. $M A T \mathbf{a}$ was deleted from all of the strains so that $H M R \mathbf{a}$-derived rings provided the sole source of a1 mRNA. In cells arrested with $\alpha$-factor or nocodazole, nucleic acids were harvested at timed intervals following galactose addition. (A) Northern analysis of a1 gene silencing in cells arrested by $\alpha$ factor in $G_{1}$. Blots were hybridized sequentially with probes to $\mathbf{a} 1$ and the ACT1 gene. When normalized to ACT1, the levels of a1 mRNA in lanes 1 and 4 are comparable. $(B)$ Chloroquine gel electrophoresis of DNA rings from $\alpha$-factor-arrested cells. Centers of the topoisomer distributions were determined by the Gaussian method and marked with an arrowhead for clarity. Changes in DNA supercoiling were attributable to changes in chromatin structure and not due to the mechanics of transcription because rings that lacked promoters also bore SIR-dependent DNA topology changes (Cheng et al. 1998). (C) Analysis of a ring lacking silencers from cells arrested at $\mathrm{G}_{2} / \mathrm{M}$ with nocodazole.

$360 \mathrm{~min}$, the expression level approached that seen in a sir3 strain (lanes 1,3,4). In contrast, the a1 transcript was never observed if the ring contained both the $E$ and $I$ silencers (lanes 6-8). These data indicate that silencers are required for maintenance of repression in $G_{1}$-arrested cells and that absence of the cis-acting elements results in deterioration of the repressed state in a time-dependent fashion. 
The appearance of a ring-encoded a 1 transcript suggested that changes in chromatin structure occur to relieve transcriptional repression following the removal of silencers. To test this idea more directly, we measured the level of supercoiling in excised DNA rings by electrophoresis in gels containing chloroquine. Previously, we showed that changes in the supercoiling of HMRaderived rings correlated closely with transitions between silent and nonsilent states (Cheng et al. 1998). This is recapitulated in Figure 2B with rings from $\alpha$-factor-arrested cells. At the earliest time point following excision (60 $\mathrm{min}$ ), a ring lacking silencers was more negatively supercoiled by one to two turns when isolated from a SIR3 strain then when isolated from a sir3 strain (lanes $1,2)$. However, by $210 \mathrm{~min}$ the supercoiling shift of the ring from the SIR3 strain was slightly diminished, and by $360 \mathrm{~min}$ the supercoil density of the ring matched that of the ring from the sir3 strain (lanes 1,3,4). In contrast, the SIR-dependent supercoiling shift of the ring containing silencers did not change during the course of the experiment (lanes 6-8). These results indicate that silencers are required continuously in $\mathrm{G}_{1}$-arrested cells to maintain the alternate chromatin structure that is associated with transcriptional repression.

Cell cycle arrest in response to mating pheromones is mediated by a mitogen-activated protein (MAP) kinase pathway that triggers numerous physiological changes, including the hyperphosphorylation of Sir3 (Stone and Pillus 1996). Although activation of the pathway has been shown to strengthen telomeric silencing, repression of the extrachromosomal rings lacking silencers might be adversely affected. To test whether the persistence of silent chromatin structure was influenced by either $\alpha$-factor treatment or $\mathrm{G}_{1}$ arrest, we examined the level of supercoiling of DNA rings in cells that had been arrested at $\mathrm{G}_{2} / \mathrm{M}$ with the microtubule destabilization agent nocodazole (Jacobs et al. 1988). Figure 2C shows that the supercoiling shift of a ring lacking silencers in nocodazole-arrested cells was similar to that in $\alpha$-factorarrested cells (cf. Fig. 2B). Sixty minutes after the induction of the recombinase, the ring was more negatively supercoiled when isolated from a SIR3 strain than when isolated from a sir3 mutant (lanes 1,2). At later time points, however, the altered supercoiling level of the ring reverted to that of the sir3 strain (lanes 3,4). Changes in the Sir-dependent supercoiling shift of rings that possessed silencers were not observed under these conditions (data not shown). Therefore, the role of silencers in maintaining silent chromatin is not restricted to cells arrested in $G_{1}$ by $\alpha$-factor. Rather, the results suggest that the cis-acting elements are required in a continuous manner throughout the cell cycle.

\section{Maintenance of silencing at $\mathrm{HML} \alpha$ in the absence of $\mathrm{E}$ and I silencers}

The observations described above are at apparent odds with those made by Holmes and Broach (1996), who showed that elimination of silencers from $H M L \alpha$ in $\mathrm{G}_{1}$ arrested cells did not disrupt silencing. The difference in persistence of transcriptional repression between $H M L \alpha$ and $H M R$ a could be due to a host of factors, including long-range effects associated with either of the corresponding chromosomal domains or localized effects due to the specific sequences excised. To distinguish between these possibilities, we constructed a series of excision cassettes at $H M R$ that contained sequences normally found at $H M L \alpha$. The $H M L$-based fragments were excised in $\mathrm{G}_{1}$-arrested cells, and persistence of the silent state was evaluated by measuring supercoil density of the resulting DNA rings. Figure 3 shows that the topoisomer distribution of a ring containing the $\alpha$ mating-type genes, but lacking silencers, remained constant during the 360-min experiment (lanes 2-4). At all times examined, the ring bore approximately one to two additional negative supercoils when isolated from a SIR3 strain than it did when isolated from a sir3 mutant. This result indicates that $\alpha$ genes, unlike a genes in Figure 2, maintain a silent chromatin structure upon excision and uncoupling from silencers at an HM locus.

Phenotypic evidence of persistent $\alpha$ gene repression was obtained to support the structural data. In MATa or $\Delta$ mat haploid strains, $\alpha$-factor treatment causes cells to arrest with an elongated shmoo morphology. If, however, the $H M L \alpha$ locus is derepressed (e.g., by inactivation of a conditional sir3 gene), cells adopt the $\mathbf{a} / \alpha$ or $\alpha$ mating profile and rapidly escape $\alpha$-factor-imposed arrest (Holmes and Broach 1996). Therefore, appearance of new buds in arrested cells can serve as a morphological marker for loss of silencing. A $\Delta$ mat strain, THC62, was

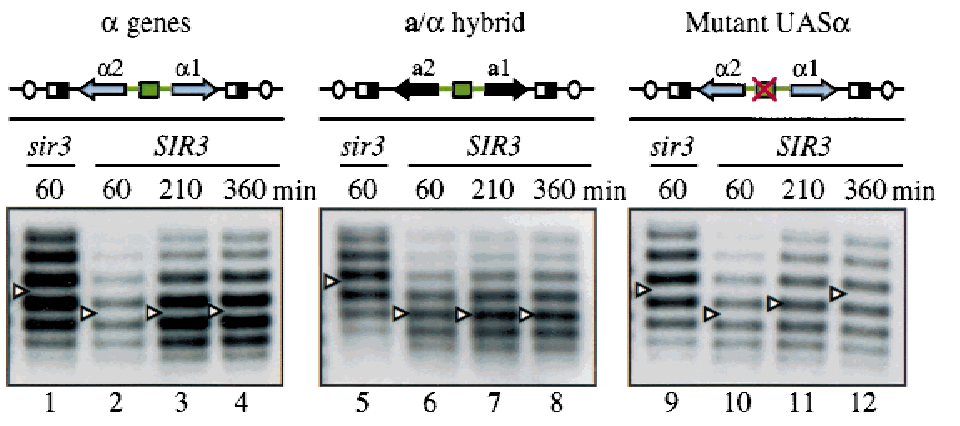

Figure 3. UAS $\alpha$ maintains silencing in the absence of silencers. Following treatment with $\alpha$-factor, DNA rings were formed in the following isogenic strain pairs: THC59 $\Delta$ hmr::rHMR $\alpha$ sir3::HIS3 (lane 1), THC62

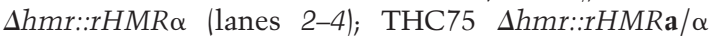
$\Delta$ sir3::HIS3 (lane 5), THC77 $\Delta$ hmr::rHMRa/ (lanes 6-8); THC68 $\Delta$ hmr::rHMR $\alpha(\operatorname{rap} 1 \mathrm{pm}) \Delta$ sir3::HIS3 (lane 9), THC69 $\Delta h m r:: r H M R \alpha(r a p 1 p m)$ (lanes 10-12). Diagrams of the excision cassettes are shown above each panel with UAS $\alpha$ depicted as a green box. DNA rings were examined as in Fig. 2. Asynchronous cultures of THC59, THC75, and THC68 were used as nonsilent control because these sir3 strains contain $H M L \alpha$ and do not respond to $\alpha$-factor. However, the supercoiling of rings in sir3 strains was influenced negligibly by $\alpha$-factor arrest (data not shown). 
treated with $\alpha$-factor, and a DNA ring containing a copy of the repressed $\alpha$ genes was excised from $H M R$. Greater than $98 \%$ of the cells adopted the shmoo morphology. Strikingly, no new buds emerged during the $6 \mathrm{hr}$ incubation period following galactose-induced ring formation, indicating that expression of ring-borne $\alpha$ genes did not occur (data not shown). Together, these results show that silencing of the $\alpha$ genes, unlike the a genes, persists in $\mathrm{G}_{1}$-arrested cells in the absence of silencers.

\section{A Rap1-binding site in the a gene UAS contributes to silencing at $\mathrm{HML}$}

The a and $\alpha$ mating-type loci are remarkably similar in primary sequence organization (Astell et al. 1981). The most notable difference is the $\mathrm{Y}$ region that spans the divergent a $1 / \mathbf{a} 2$ promoters and the $\mathbf{a} 1$ gene at $H M R \mathbf{a}(\mathrm{Ya})$ versus the $\alpha 1 / \alpha 2$ promoters and the $\alpha 1$ gene at $H M L \alpha$ $(\mathrm{Y} \alpha)$. To identify the sequence determinants that facilitate maintenance of silencing at $H M L$, an $\mathrm{HMR} / \mathrm{HML}$ hybrid excision cassette was constructed in which the divergent a gene promoters were replaced with a fragment containing the $\alpha$ gene promoters (Fig. 3, middle). When this hybrid ring was excised from $H M R$ in $\mathrm{G}_{1}$ arrested cells, the ring bore a SIR-dependent alteration in DNA supercoiling that did not change throughout the 360-min time course (lanes 6-8). This result indicates that a site within the $\alpha$ gene promoter region is sufficient for maintenance of preassembled silent chromatin.

We hypothesized that the $\alpha$ gene promoters recruited a protein that favored the persistence of silencing. A wellcharacterized binding site for the silencer binding protein Rap $1 p$ within the $\alpha$ gene UAS (UAS $\alpha$ ) represented a likely candidate. When the $\alpha$ genes are located at MAT, binding of the dual function protein to the site is required for expression (Giesman et al. 1991; Kurtz and Shore 1991). Footprinting studies have shown that a region encompassing the 15-bp UAS $\alpha$ is not occluded by nucleosomes at $H M L$, indicating that the site might be available to Raplp, even within the silent chromatin (Weiss and Simpson 1998). To test whether the UAS $\alpha$ contributes to silencing of the genes when they are located at an HM locus, we examined the supercoiling of a ring bearing a nonfunctional Raplp-binding site. The central cytosine of the conserved CCC triplet of the Rap1 site was converted to an adenosine, a mutation that blocks transactivation of MAT $\alpha$ in vivo and prevents the binding of Raplp in vitro (Vignais and Sentenac 1989; Giesman et al. 1991). Sixty minutes after excision the mutated and nonmutated rings produced similar SIR-dependent supercoiling shifts (Fig. 3, lanes 2,10). At later time points, however, the ring with the mutant Raplpbinding site reverted back to the nonsilent state (cf. lanes 11 and 12 to lanes 3 and 4). Together, these results indicate that the Rap1p-binding site in UAS $\alpha$ is both necessary and sufficient for maintenance of the repressed state in rings that lack silencers.

A sensitive genetic assay was used to test whether UAS $\alpha$ contributes to silencing at the chromosomal HML locus. A chimeric reporter gene in which the URA3 pro- moter was fused to the ADE2 ORF was integrated between $\alpha 2$ and the HMLE silencer (Fig. 4). Cells that express $A D E 2$ give rise to white colonies on media containing low adenine, whereas cells that do not express the gene give rise to red colonies (Roman 1957). Cells containing URA3P-ADE2 at $H M L$ produced uniformly red colonies (Fig. 4, left), indicating that the reporter gene was silenced. When the gene was integrated at a derivatized $H M L$ locus that contained a point mutation in the UAS $\alpha$ Rap1 site, a mixture of derepressed white colonies, partially repressed pink colonies, and fully repressed red colonies was observed (Fig. 4, right). Some colonies were either predominantly red or white but contained small sectors of the opposite color, indicating that a stable switch between expression states occurred during colony formation. The data reveal that the Raplpbinding site in the $\alpha$ gene promoters is a significant contributor to repression of the genes when they are located at $H M L$.

\section{Elevated levels of Sir3p and Sir4p stabilize rings of silent chromatin}

Silencing of the HM loci is compromised when they are ectopically positioned far from telomeres where the Sir proteins are normally concentrated (Thompson et al. 1994; Maillet et al. 1996). The defect can be suppressed, however, by overexpressing a subset of the SIR genes. To test whether elevated SIR gene dosage would improve silencing in a ring that lacked silencers, a strain carrying the excision cassette shown in Figure 1A was transformed with CEN -based plasmids carrying SIR1, SIR2, SIR3, or SIR4. Maintenance of silencing was then measured in $\mathrm{G}_{1}$-arrested cells. Figure $5 \mathrm{~A}$ shows that SIR-

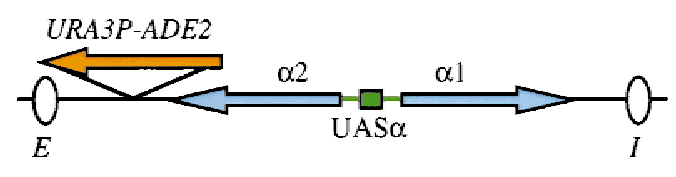

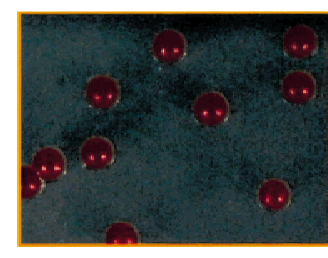

wt UAS $\alpha$

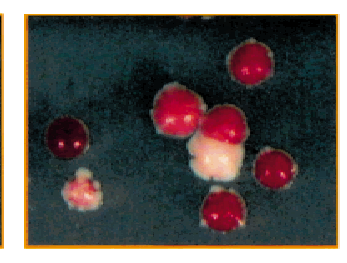

mutant UAS $\alpha$
Figure 4. UAS $\alpha$ contributes to silencing of the chromosomal $H M L \alpha$ locus. Strains THC74 hml::URA3P-ADE2 and THC76 hml(rap1pm)::URA3P-ADE2 were plated on SC media containing minimal adenine after overnight growth on nonselective media. Red or pink pigmentation corresponds to full or partial repression of $A D E 2$, respectively. Unpigmented (white) colonies correspond to complete $A D E 2$ derepression. Previously, the $U R A 3 P-A D E 2$ construct was used to monitor transcriptional repression at HMRa (Rivier et al. 1999). The URA3 promoter is up-regulated when uracil is omitted from the growth media. On SC plates lacking uracil, more frequent derepression was observed in the UAS $\alpha$ mutant strain (data not shown). 
A

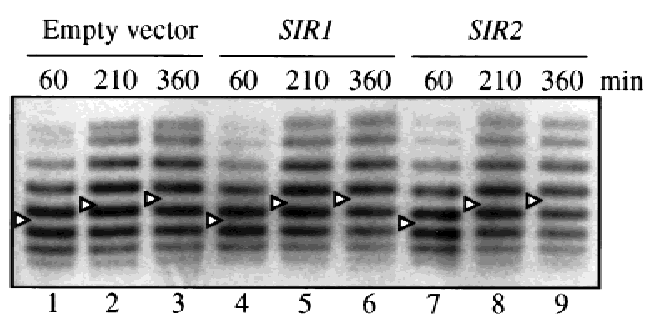

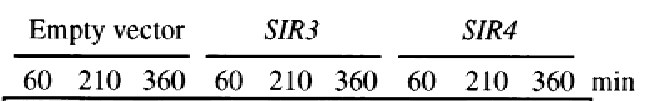

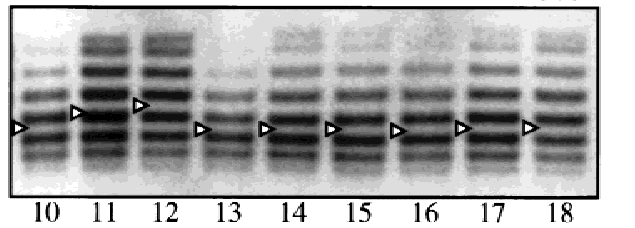

B

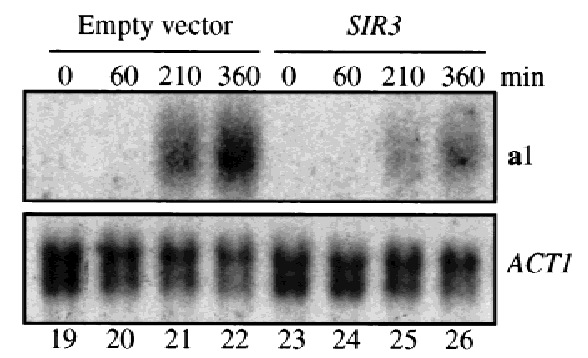

Figure 5. Stabilization of silent chromatin rings by elevated SIR gene dosage. Strain THC43 hmr::rHMRa was transformed with single copy, CEN-based vectors pJR910 (SIR1, lanes 4-6), pJR69 (SIR2, lanes 7-9), pJR273 (SIR3, lanes 13-15, 23-26), pJR368 (SIR4, lanes 16-18), or pRS416 (empty vector, lanes 1-3, 10-12, 19-22). In each case, the gene of interest was transcribed from its own promoter. Supercoiling of DNA rings $(A)$ and RNA levels $(B)$ were examined as in Fig. 2.

dependent supercoiling shift of the ring did not persist in cells containing empty vector or an extra copy of SIR 1 or SIR2 (lanes 1-9). In all three cases, the rings reverted to the level of supercoiling associated with the derepressed state. This result indicates that neither Sirlp nor Sir2p is limiting for maintenance of silencing under these conditions. In contrast, the silent state was stabilized by an extra copy of either SIR3 or SIR4 (lanes 13-18). Particularly in the case of elevated SIR3 expression, supercoiling levels of the ring remained roughly constant throughout the duration of the experiment. Minor changes in the distribution of ring topoisomers probably reflect the presence of cells in the population that have lost the SIR expression vectors.

Northern analysis of the a1 transcript confirmed the structural data. Appearance of a1 mRNA following excision in strains containing an extra copy of SIR3 was greatly reduced relative to strains that contained empty vector (Fig. 5B). These results indicate that elevated expression of the Sir3p and Sir $4 p$ structural components of the silent chromatin increases the persistence of the repressive structure, even in the absence of silencers.

\section{Preassembled silent chromatin is stabilized} by Sir3p overexpression in $G_{1}$

Stabilization of repressed rings by elevated Sir3p or Sir $4 p$ levels could occur during the establishment or maintenance phases of silencing. Conceptually, extra Sir proteins could facilitate the establishment of a more stable repressive structure. Alternatively, extra Sir proteins could add to and stabilize a pre-existing repressive structure. To determine whether elevated Sir3p increases the stability of preassembled silent chromatin, we induced expression of the protein in $\alpha$-factor-treated cultures. Arrest with the pheromone in $G_{1}$ prevents cells from transiting through $\mathrm{S}$ phase, the period during which establishment of silencing is known to occur.

Induction of Sir3p was achieved with a chromosomally integrated SIR3 gene fused to the GAL10 promoter (GAL10P-SIR3). This tightly regulated construct provided functional Sir3p at nontoxic levels when induced (see Materials and Methods). Following uniform $\mathrm{G}_{1}$ arrest, Sir3p and recombinase production were induced simultaneously by the addition of galactose. Recombination yielded the ring shown in Figure 1A. In a SIR3 strain, production of additional Sir3p prevented loss of silencing of the ring (Fig. 6). The initial SIR-dependent DNA supercoiling level of the ring was maintained throughout the duration of the experiment (lanes 4-6). This result indicates that elevation of Sir3p levels can stabilize preassembled silent chromatin, even without passage through $\mathrm{S}$ phase.

To test whether non-S-phase expression of Sir3p could silence a locus that was initially derepressed, we induced GAL10P-SIR3 in a sir3 mutant strain. As before, cells were uniformly arrested in $\mathrm{G}_{1}$ with $\alpha$-factor and coproduction of recombinase and Sir3p was induced. Upon excision, the ring bore a nonsilent DNA topology (Fig. 6; cf. lanes 3 and 7) This condition was not changed by $>6$ $\mathrm{hr}$ of Sir3p expression (lanes 8,9). Therefore, Sir3p cannot impart silencing de novo to a derepressed locus in noncycling cells. Apparently, stabilization of silent chroma-

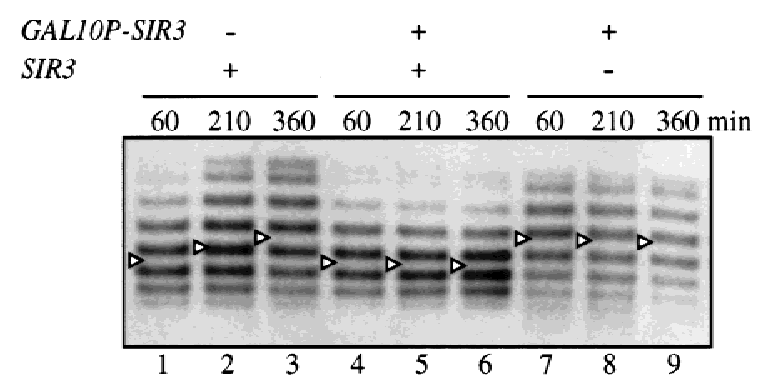

Figure 6. Stabilization of silent chromatin rings by elevated SIR3 expression in $\mathrm{G}_{1}$-arrested cells. Strains THC43 hmr::rHMRa (lanes 1-3), THC57 hmr::rHMRa ura3-1::GAL10PSIR3::URA3 (lanes 4-6), and THC70 hmr::rHMRa $\Delta$ sir3::HIS3 ura3-1::GAL10P-SIR3HA::URA3 (lanes 7-9) containing recombinase expression vector pHM153 were arrested with $\alpha$-factor. Subsequently, expression of the $R$ recombinase gene and SIR3 were induced simultaneously with galactose. Supercoiling of DNA rings was examined as in Fig. 2. 
tin by Sir3p in non-S-phase cells requires a pre-existing silent chromatin to be in place (lanes $4-6)$. The result is consistent with a requirement for passage through $S$ phase to establish silencing (Miller and Nasmyth 1984; Fox et al. 1997). It seems likely that some specialized feature of chromatin assembly, such as histone deposition or modification, represents the critical S-phase event in the establishment of silent chromatin.

\section{Association of Sir3p with silent chromatin does not require $S$-phase passage}

Stabilization of the silent chromatin by Sir3p expression in non-S-phase cells could occur directly by incorporation of the protein into chromatin or by less direct means. To determine whether the protein was incorporated into preassembled silent chromatin structure, chromatin immunoprecipitation assays (ChImp assays) were performed with an induced, HA-tagged Sir3 derivative, Sir3HAp. Following uniform $\mathrm{G}_{1}$ arrest, the epitopetagged protein was expressed from a GAL1OP-SIR3HA gene fusion. Immunoprecipitations were performed with anti-HA antibody and sonicated extract from formaldehyde cross-linked cells. Coimmunoprecipitation of representative genomic loci, including the a1 gene at HMRa, as well as GAL1, ACT1, and PHO5, were evaluated by PCR using corresponding primer pairs. Figure 7 shows that a1 was selectively precipitated upon induction of SIR3HA in a SIR3 strain (lane 3). Precipitation of

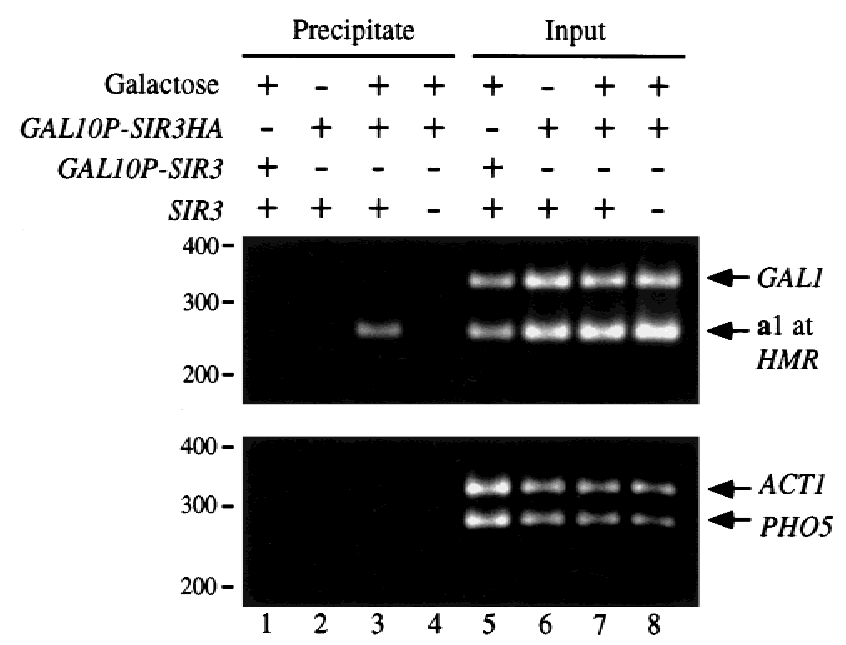

Figure 7. Incorporation of Sir3p into silent chromatin in $\mathrm{G}_{1}$ arrested cells. Strains THC57 ura3-1::GAL1OP-SIR3::URA3 (lanes 1,5), THC67 ura3-1::GAL10P-SIR3HA::URA3 (lanes 2,3,6,7), and THC70 $\Delta$ sir3::HIS3 ura3-1::GAL10P-SIR3HA::URA3 (lanes 4,8) were arrested with $\alpha$-factor. Following induction of SIR3 expression with galactose, cells were treated with formaldehyde. Processed samples were immunoprecipitated with antiHA antibody, and the precipitated material was probed for the presence of DNA with PCR using primer pairs specific for the a1, GAL1, ACT1, and PHO5 genes. The MATa locus was deleted from all of these strains so that HMRa provided the sole copy of a1 DNA. The positions of DNA mobility standards are marked at left. the gene did not occur if Sir3HAp was not induced or if the epitope was removed from the expression vector (lanes 1,2). Finally, Sir3HAp was not incorporated into chromatin at a1 in a sir3 strain (lane 4), in agreement with the DNA supercoiling data in Figure 6 (lanes 7-9). These data show that incorporation of Sir3p into the silent chromatin is not restricted to $S$ phase. The results suggest that yeast heterochromatin is a dynamic structure that possess the ability to exchange chromatinbound Sir3p for soluble unbound protein throughout the cell cycle.

\section{Discussion \\ Silencers are required continuously to maintain silent chromatin}

Heritable propagation of the stably repressed state at $H M$ loci requires that (1) a heterochromatin-like structure be re-established following each round of DNA replication, and (2) that the structure be maintained throughout the duration of the cell cycle. A role for silencers in establishment of silencing is already well appreciated. Relocation of silencers to some ectopic loci can result in the silencing of adjacent genes (Lee and Gross 1993; Shei and Broach 1995; Maillet et al. 1996). In this report we have examined the role of silencers in the maintenance of the silent state and found that the elements contribute a critical function at this stage too. By unlinking fragments of preassembled silent chromatin from silencers in vivo, we have shown that silencers are required in cis to preserve silent chromatin; in $\mathrm{G}_{1}$-arrested cells, removal of silencers resulted in reactivation of silenced genes and loss of SIR-dependent alterations in DNA supercoiling (Fig. 2). Similar observations were made in cells arrested at $\mathrm{G}_{2} / \mathrm{M}$ using nocodazole. These findings demonstrate that silencers act in a continuous manner to maintain the structure and function of silent chromatin.

\section{A protosilencer maintains silencing in the absence of silencers}

The conclusion that silencers maintain silent chromatin is supported by our parallel studies of the a and $\alpha$ matingtype genes positioned at $H M R$. Unlike the situation with the a genes, uncoupling of the $\alpha$ gene pair from flanking silencers resulted in silent DNA rings that were stably repressed in arrested cells (Fig. 3). Persistent silencing in this case relied on a cis-acting silencing element located within the $\alpha$ gene promoter. By point mutation and addback experiments we showed that the Rap1-binding site constituting UAS $\alpha$ was both necessary and sufficient for repression in the absence of silencers. On the basis of this observation, we conclude that silencers, as well as individual silencer binding site sequences, are sufficient to maintain the silent state. Isolated binding sites for silencer binding proteins, termed protosilencers, although lacking intrinsic silencing function, have been shown to interact cooperatively with intact silencers to 
strengthen silencing (Boscheron et al. 1996). Specifically, repression of a sensitive reporter gene by a sole silencer was aided by tethering either Raplp, Abflp, or ORC to a DNA site $4 \mathrm{~kb}$ away. By inference, it was posited that the Rap1p-binding site at UAS $\alpha$ might contribute similarly to silencing at $H M L$. That UAS $\alpha$ performs this function in a near native chromosomal context was demonstrated by comparing wild-type and mutant UAS $\alpha$ sequences in a colony color assay for derepression (Fig. 4). The Rap1 protein (repressor/activator protein) derived its name from the discovery that it contributes to either transcriptional repression when bound to silencers or transcriptional activation when bound at the promoters of numerous genes, including MAT $\alpha$ (Shore 1994). UAS $\alpha$ provides the first example of a specific Raplp site that possesses dual function, either activating or repressing the associated gene/genes, depending on the chromosomal context of the gene/genes.

Holmes and Broach (1996) have argued that maintenance of repression does not require silencers because derepression of the $\alpha$ genes did not occur when they removed the $E$ and $I$ silencers from $H M L$ in $\mathrm{G}_{1}$-arrested cells. This conclusion must now be reconsidered in light of the discovery that UAS $\alpha$ functions as a protosilencer. Nonetheless, silencers were shown to be required for inheritance of the silent state; following removal of the elements, reactivation of $H M L$ occurred within a single cell cycle, particularly during passage between the $G_{1}$ and $G_{2}$ stages of the cell cycle (Holmes and Broach 1996; Bi and Broach 1997). Remarkably, reactivation occurred even in the absence of DNA replication of the silent template. We too have found that nonreplicating DNA rings containing the UAS $\alpha$ protosilencer reactivated during this interval (T.-H. Cheng, unpubl.). Although critical constructs of Bi and Broach (1997) lacked UAS $\alpha$, it should be noted that they did contain regions of $H M L$ and bacterial DNA fragments not present in our clones. It is possible that a sequence with protosilencer activity resided within this additional DNA. In either case, the results indicate that protosilencers on their own are not capable of propagating the silent state. Whereas the elements can prevent loss of silencing in $G_{1}$, they do not suffice during subsequent cell cycle progression. In this regard, bona fide silencers appear either to be more efficient or to provide additional functions.

\section{Silent chromatin is dynamic}

How do silencers function in the preservation of silent chromatin? The answer may lie in the relationships between Sir protein availability, recruitment, and silent chromatin stability. Sir proteins have been shown previously to be limiting for repression at HM loci due to competition for the factors by telomeres where Sir-mediated repression also occurs (Aparicio et al. 1991; Buck and Shore 1995; Marcand et al. 1996). In a number of studies, alteration of the level of free Sir2p, Sir3p, or Sir4p influenced either the efficiency of the silencing of reporter constructs or the span of the silenced domain (Renauld et al. 1993; Sussel et al. 1993; Maillet et al.
1996; Enomoto and Berman 1998). Here, persistence of silencing in DNA rings was shown to be extended by increasing the levels of Sir3p and Sir4p (Figs. 5 and 6). The striking feature was that stabilization by elevated Sir3p did not require passage through S phase. Moreover, stabilization appeared to be the result of direct incorporation of the protein into the repressive structure (Fig. 7). These findings demonstrate that recruitment of Sir factors can occur during maintenance of the silent state, as well as during its establishment. Together with the facile loss of silent chromatin upon removal of silencers, the observations indicate that silent chromatin is dynamic with critical components, such as Sir3p, equilibrating on and off the structure. Therefore, a reasonable role for silencers during maintenance may be to continually recruit new Sir proteins. For example, if silencing components turn over naturally, due either to dissociation or degradation, cis-acting elements would promote replenishment of the depleted components. Recruitment could be facilitated by direct protein-protein interactions with silencer-bound proteins, as described above, as well as by silencers targeting silent chromatin to regions of the nucleus that are enriched in Sir proteins (Andrulis et al. 1998).

Silencers are not likely to act alone in recruitment of the Sir proteins. A large network of protein-protein interactions could favor binding of free Sir proteins by those already bound. Sir3p and Sir4p form homomeric and heteromeric complexes (Chien et al. 1991; Moretti et al. 1994), and Sir2p and Sir4p also form a complex (Moazed and Johnson 1996; Strahl-Bolsinger et al. 1997). In addition, Sir3p and Sir4p bind preferentially to hypoacetylated amino-terminal tails of histones $\mathrm{H} 3$ and $\mathrm{H} 4$ (Hecht et al. 1995), which are enriched at the silent loci (Braunstein et al. 1993). Finally, tethering Sir3p and Sir4p to DNA directly leads to repression of adjacent genes (Lustig et al. 1996; Marcand et al. 1996). This last example demonstrates that silencers can be bypassed if a high local concentration of Sir protein is maintained. Conceivably, pre-existing silent chromatin could be propagated by self-recruitment if the intracellular concentration of Sir proteins was elevated. In flies and humans, such a mechanism has been proposed to explain the epigenetic behavior of kinetochores, the specialized chromatin-based structures that segregate chromosomes (Murphy and Karpen 1998; Wiens and Sorger 1998, and references therein). Functional kinetochores sometimes assemble on noncentromeric locations, where they are propagated in a heritable fashion despite the lack of discernible centromeric DNA sequences. Perpetuation of this class of kinetochores may rely entirely on self-templating by the pre-existing chromatin structure. In yeast, Sir2p and Sir3p must be maintained at low levels because they are toxic, potentially due to the promiscuous silencing of critical genes (Holmes et al. 1997). Therefore, silencers may have evolved to recruit Sir proteins efficiently and specifically to the HM loci in an environment where telomeres and other sites, such as rDNA (Smith et al. 1998), compete for limited pools of Sir proteins. 
Enomoto and Berman (1998) showed that maintenance of silent chromatin was influenced by mutations in a replication-coupled chromatin assembly factor encoded by the $C A C$ genes. In $\mathrm{G}_{1}$-arrested cac mutants, derepression of the mating-type loci in individual cells was recorded with a sensitive time-lapse microscopy assay. These investigators argued that a defect during silent chromatin assembly was manifest in a metastable repressive structure that could not be maintained appropriately. Given our results, an alternative testable hypothesis is that the chromatin assembly factor acts directly on preassembled silent chromatin in $\mathrm{G}_{1}$-arrested cells to maintain the silent state. In support of this notion, the mouse Cac1p homolog CAF-1 p150 was shown recently to associate with heterochromatin in non-Sphase cells (Murzina et al. 1999).

\section{Maintenance of repressed chromosomal domains in other organisms}

Variegated repression of genes adjacent to heterochromatin is thought to occur by the stochastic but stable spread of heterochromatic structure into adjacent DNA. It was shown recently that reporter genes subject to this form of repression in Drosophila reactivated upon excision from the genome, even in mitotically quiescent cells (Ahmad and Golic 1996). This observation indicates that maintenance of heterochromatic repression in flies, like yeast, requires preservation of proper genomic context. It is not clear whether loss of continuity with chromosomal heterochromatin or nuclear compartmentalization accounts for reactivation in the Drosophila studies. However, recombination-based studies with engineered excision cassettes hold promise of identifying cis-acting sequences sufficient for maintenance of heterochromatic repression.

Maintenance of the inactive X chromosome (Xi) in female mammals is notably different from examples in yeast and flies. Like yeast, establishment of the repressed state requires a cis-acting regulatory element, the $\mathrm{X}$ inactivation center $(X I C)$. However, inactivation of $\mathrm{Xi}$ is heritably propagated following removal of XIC, indicating that the element is not required for maintenance of the repressed state (Brown and Willard 1994). Xi is structurally distinct in numerous ways, including differential DNA methylation, histone acetylation, and the presence of an RNA chromatin component (Lee and Jaenisch 1997, and references therein). Any one of these features could participate in a self-templating mechanism to propagate heterochromatic repression. It also seems possible that the X chromosome contains stabilization elements, like protosilencers of yeast, that promote maintenance of repression but that lack the ability to establish repression on their own. Based on Xi-autosome translocation data, Gartler and Riggs (1983) postulated early on that the $\mathrm{X}$ chromosome contains stabilization elements that serve as "booster" sites to help spread heterochromatic structure throughout Xi. It was posited recently that long interspersed nuclear elements (LINEs), which are enriched in the $\mathrm{X}$ chromosome (Boyle et al.
1990), function in this way (Lyon 1998). Precedent for booster sites is found in yeast where native protosilencers within subtelomeric repeat sequences propagate silencing away from chromosomal termini (Fourel et al. 1999; Pryde and Louis 1999). Although the mechanisms of booster site action may differ widely between humans and yeast, the underlying requirement for amplification of a silencing signal along the chromosome appears to be conserved.

\section{Materials and methods}

\section{Strain and plasmid constructions}

$\mathrm{p} \Delta \mathrm{hmra}: \mathrm{rHMR} \alpha$ was constructed by replacing the entire a gene fragment within the excision cassette of phmr::rA1A2 (Cheng et al. 1998) with a PCR fragment containing the $\alpha$ genes from $H M L$ (chromosome III coordinates 11695-14018). $\mathrm{p} \Delta \mathrm{hmra}: \mathrm{rHMR} \alpha(\mathrm{rap} 1 \mathrm{pm})$ was derived from $\mathrm{p} \Delta \mathrm{hmra:} \mathrm{rHMR} \alpha$ by using overlap PCR to introduce a C-to-A transversion in the Raplp-binding site of UAS $\alpha$ (see Results). p $\Delta \mathrm{hmr}:: \mathrm{rHMRa} / \alpha$ was obtained by inserting a PCR fragment containing the $\alpha$ gene divergent promoters (coordinates 12909-13332) into phmr::rA1A2 $\Delta$ p at a $B a m H I$ site that replaced the a gene promoters (Cheng et al. 1998). pRS406GAL10P-SIR3 was obtained by ligating a EcoRV-BamHI fragment that contained a GAL1OP-SIR3 chimeric gene from pAR42 (S. Holmes, Wesleyan University, Middletown, CT) into the multiple cloning site of pRS406. pRS406GAL10P-SIR3HA was generated by replacing the carboxyl terminus of SIR3 in pRS406GAL10P-SIR3 (XbaI-XhoI) with an HA-tagged version from pRS416-SIR3HA (Ansari and Gartenberg 1999). phmla::URA3P-ADE2 was derived from plasmid puc19-HML (D. Shore, University of Geneva, Switzerland) by replacing the EagI-ClaI fragment of $H M L$ with a $2.0-\mathrm{kb}$, PCR-amplified fragment that contained the URA3P-ADE2 chimeric gene from plasmid pDR859 (D. Rivier, University of Illinois, Urbana-Champagne). phml $\alpha$ (raplpm)::URA3P-ADE2 was constructed by replacing the

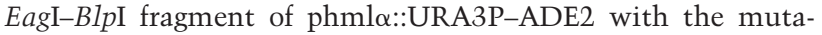
genized version from $\mathrm{p} \Delta \mathrm{hmr}: \mathrm{rHMR} \alpha(\operatorname{rap} 1 \mathrm{pm}) \cdot \mathrm{p} \Delta$ mata::TRP1 was created by replacing the ApaI-SmaI fragment of $\mathrm{p} \Delta$ mat::URA3 with a $1.6-\mathrm{kb}$ fragment (ApaI-SnaBI) containing the TRP1 gene from pRS414 (Cheng et al. 1998). Plasmids pJR910, pJR69, pJR273, and pJR368 were constructed in the laboratory of J. Rine (UC, Berkeley) and provided by J. Berman (University of Minnesota, St. Paul).

Unless specified otherwise, all strains were constructed by the one-step gene disruption method and confirmed by Southern hybridization. THC42 was derived from THC23 in three steps: (1) LYS2 was disrupted with plasmid pUC18- 1 lys2 (Cheng et al. 1998); (2) BAR1 was disrupted with plasmid pTM47 (Menees and Sandmeyer 1994); and (3) MATa was disrupted with $\mathrm{p} \Delta$ mata::TRP1. THC78 was derived from THC42 by replacing the $\alpha$ genes at $H M L \alpha$ with a PCR-amplified kanMX gene from plasmid pUG6 (Wach et al. 1994). THC51 was derived from THC42 by replacing the a genes at HMRa with URA3, as described previously (Cheng et al. 1998). THC59, THC68, and THC75 were derived from THC51 by replacing the $\Delta$ hmr::rURA3 locus with modified $h m r$ loci from plasmids p $\Delta$ hmra::rHMR $\alpha, \quad \mathrm{p} \Delta$ hmra::rHMR $\alpha(\operatorname{rap} 1 \mathrm{pm})$, and p $\Delta$ hmra::rHMRa/ $\alpha$, respectively. THC43, THC62, THC69, and THC77 were derived from THC42, THC59, THC68, and THC75, respectively, by regeneration of chromosomal SIR3 using pAR3. THC57 and THC67 were derived from THC43 by targeted integration of one copy of pRS406GAL10P-SIR3 and 
pRS406GAL10P-SIR3HA, respectively, into ura3-1. THC70 was derived from THC78 by targeted integration of one copy of pRS406GAL10P-SIR3HA into ura3-1. THC37 was derived from YCL1 (Cheng et al. 1998) by disrupting MATa with p $\Delta$ mat::URA3. THC79 was derived from YCL2 (Cheng et al. 1998) by disrupting $M A T$ a with $\mathrm{p} \Delta$ mat::URA3 and replacing the $\alpha$ genes at $H M L \alpha$ with kanMX. Strains THC74 and THC76 were derived from PJ1 (W303-1A URA3) by replacing $H M L \alpha$ with modified loci in plasmids phmla::URA3P-ADE2 and phml $\alpha(\operatorname{rap} 1 \mathrm{pm})::$ URA3P-ADE2, respectively. Selection of PJ1 derivatives was aided by prior transformation with an "antisir" plasmid, pCTC23 (Chien et al. 1998), which was subsequently evicted. Note that chromosomal excision cassettes $h m r:: r H M R \mathbf{a}$ and $h m r:: r H M R \mathbf{a}+E I$ previously were named hmr::rA1A2 and hmr::rHMR, respectively (Cheng et al. 1998).

\section{Cell growth and analysis of nucleic acids}

Strains were transformed with a recombinase expression vector (pHM153) and grown at $30^{\circ} \mathrm{C}$ in synthetic dropout media containing $2 \%$ raffinose. At mid-log phase, cells were treated for 3 hr with $2 \mu \mathrm{g} / \mathrm{ml} \alpha$-factor (Sigma) for $\Delta$ bar1 strains and $10 \mu \mathrm{g} / \mathrm{ml}$ pheromone for BAR1 strains. Persistent $\alpha$-factor-mediated arrest in $G_{1}$ was confirmed by flow cytometry and/or visual inspection of cell morphology. Nocodazole-mediated arrest at $\mathrm{G}_{2} / \mathrm{M}$ was achieved by treatment with $10 \mu \mathrm{g} / \mathrm{ml}$ nocodazole (Sigma) for $3 \mathrm{hr}$. Approximately 90\% of the cells arrested with large buds (dumbbell shaped), indicative of $\mathrm{G}_{2} / \mathrm{M}$ block, and remained in this configuration for the duration of the experiment.

DNA ring formation was induced with galactose $\left(C_{f}=2 \%\right)$, and parallel aliquots of culture were used for both Northern blots and DNA supercoiling analyses. Isolation, electrophoresis, and detection of nucleic acids were described previously (Cheng et al. 1998). Topoisomer distributions were evaluated by the Gaussian method following electrophoresis in gels containing 2 $\mathrm{\mu g} / \mathrm{ml}$ chloroquine, such that more negatively supercoiled rings migrated more rapidly (Depew and Wang 1975).

\section{Colony color assays}

Uniformly red colonies of strains THC74 and THC76 were grown overnight in nonselective liquid media (YPDA) and plated on SC plates that contained limiting adenine $(6 \mu \mathrm{g} / \mathrm{ml})$. Following 2 days of incubation at $30^{\circ} \mathrm{C}$, plates were stored for 3 days at $4^{\circ} \mathrm{C}$ for enhanced color development.

\section{Characterization of integrated GAL10P-SIR3 fusions}

Overexpression of SIR2 and SIR3 from high copy vectors is cytotoxic (Holmes et al. 1997). To verify that expression of a single integrated GAL1OP-SIR3 fusion gene was not overtly deleterious, SIR3 strains containing or lacking the chimera were grown side by side on plates containing galactose. In both cases, equivalent numbers of colonies appeared and grew at equivalent rates. Galactose-induced expression of either the GAL10P-SIR3 or GAL10P-SIR3HA was sufficient to suppress the mating defect in a sir3 strain. When the strains were grown in raffinose, however, no silencing could be detected with a quantitative mating assay and Sir3HAp could not be visualized by Western blot analysis. Together, these data show that the integrated GAL10P-SIR3 chimeras are functional, tightly regulated, yet not harmful.

\section{ChImp assays and PCR analysis}

ChImp assays were performed essentially as described in Apari- cio et al. (1997), with the following exceptions. Following cell cycle arrest with $\alpha$-factor, GAL1OP-SIR3HA expression was induced by galactose addition. After a 45-min incubation, cells were treated with formaldehyde and chromatin-containing extracts were prepared. Epitope-tagged Sir3p was immunoprecipitated with anti-HA monoclonal antibody HA.11 (BAbCO, Richmond, CA) bound to protein A-Sepharose CL-4B beads (Pharmacia, Piscataway, NJ). PCR reactions were performed with either $1 / 50$ of the precipitated DNA or $1 / 500$ of the input material. Two pairs of gene-specific primers were used simultaneously in each reaction (A1-1/A1-2 for the a1 gene and GAL1-1/GAL1-2 for the GAL1 gene, or ACT-1/ACT1-2 for the ACT1 gene and PHO5-1/PHO5-2 for the PHO5 gene). Primer sequences are as follows: A1-1 (5'-ATGGATGATATTTGTAGTATGGCG-3'); A1-2 (5'-GGTGGTATATTTCTAACCTATTGTTAG-3'); GAL1-1 (5' - CTGCAAGTCTTCTGTGAGG-3'); GAL1-2 (5'-GATACAACAAGGGTGTTCGC-3'); ACT1-1 (5'-AGACCAAGACACCAAGGTATC-3'); ACT1-2 (5'-GAGTACAAGGACAAAACGGCT-3'); PHO5-1 (5'-ACTTGACCTCAACTGACGC-3'); and PHO5-2 (5'-AGGATATCGGTATCGTGGG-3'). Twenty-five cycles of PCR were performed with an annealing temperature of $51^{\circ} \mathrm{C}$. PCR products were separated by agarose gel electrophoresis, stained with EtBr, and photographed using Polaroid 665 film.

\section{Acknowledgments}

We thank David Shore, Scott Holmes, Judith Berman, and David Rivier for kindly providing plasmids, Danny Reinberg for critical comments on the manuscript, and Ken Irvine for use of digital photography equipment. We also thank Bruce Howard for pointing out valuable references, Prahba Joy for technical assistance, and the rest of the Gartenberg laboratory for stimulating discussions. This work was funded by a grant from the NIH (GM51402).

The publication costs of this article were defrayed in part by payment of page charges. This article must therefore be hereby marked "advertisement" in accordance with 18 USC section 1734 solely to indicate this fact.

\section{References}

Ahmad, K. and K.G. Golic. 1996. Somatic reversion of chromosomal position effects in Drosophila melanogaster. Genetics 144: 657-670.

Andrulis, E., A.M. Neiman, D.C. Zappulla, and R. Sternglanz. 1998. Perinuclear localization of chromatin facilitates transcriptional silencing. Nature 394: 592-595.

Ansari, A. and M.R. Gartenberg. 1999. Persistence of an alternate chromatin structure at silenced loci in vitro. Proc. Natl. Acad. Sci. 96: 343-348.

Aparicio, O.M. and D.E. Gottschling. 1994. Overcoming telomeric silencing: A trans-activator competes to establish gene expression in a cell-cycle dependent way. Genes \& Dev. 8: 1133-1146.

Aparicio, O.M., B.L. Billington, and D.E. Gottschling. 1991. Modifiers of position effect are shared between telomeric and silent mating-type loci in Saccharomyces cerevisiae. Cell 66: 1279-1287.

Aparicio, O.M., D.M. Weinstein, and S.P. Bell. 1997. Components and dynamics of DNA replication complexes in Saccharomyces cerevisiae: Redistribution of MCM proteins and Cdc45p during S phase. Cell 91: 59-69.

Astell, C.R., L. Ahlstrom-Jonasson, M. Smith, K. Tatchell, K.A. 
Nasmyth, and B.D. Hall. 1981. The sequence of the DNAs coding for the mating-type loci of Saccharomyces cerevisiae. Cell 27: 15-23.

Bell, S.P., R. Kobayashi, and B. Stillman. 1993. Yeast origin recognition complex functions in transcription silencing and DNA replication. Science 262: 1844-1849.

Bi, X. and J.R. Broach. 1997. DNA in transcriptionally silent chromatin assumes a distinct topology that is sensitive to cell cycle progression. Mol. Cell. Biol. 17: 7077-7087.

Boscheron, C., L. Maillet, S. Marcand, M. Tsai-Pflugfelder, S.M. Gasser, and E. Gilson. 1996. Cooperation at a distance between silencers and proto-silencers at the yeast $H M L$ locus. EMBO J. 15: 2184-2195.

Boyle, A.L., S.G. Ballard, and D.C. Ward. 1990. Differential distribution of long and short interspersed element sequences in the mouse genome: Chromosome karyotyping by fluorescence in situ hybridization. Proc. Natl. Acad. Sci. 87: 77577761.

Brand, A.H., L. Breeden, J. Abraham, R. Sternglanz, and K. Nasmyth. 1985. Characterization of a "silencer" in yeast: A DNA sequence with properties opposite those of a transcriptional enhancer. Cell 41: 41-48.

Braunstein, M., A.B. Rose, S.G. Holmes, C.D. Allis, and J.R. Broach. 1993. Transcriptional silencing in yeast is associated with reduced nucleosome acetylation. Genes \& Dev. 7: 592 604.

Brown, C.J. and H.F. Willard. 1994. The human X-inactivation center is not required for maintenance of X-chromosome inactivation. Nature 368: 154-156.

Buck, S.W. and D. Shore. 1995. Action of a RAP1 carboxy-terminal silencing domain reveals an underlying competition between $H M R$ and telomeres in yeast. Genes \& Dev. 9: 370 384.

Cheng, T.-H., Y.-C. Li, and M.R. Gartenberg. 1998. Persistence of an alternate chromatin structure at silenced loci in the absence of silencers. Proc. Nat1. Acad. Sci. 95: 5521-5526.

Chien, C.-T., P.L. Bartel, R. Sternglanz, and S. Fields. 1991. The two-hybrid system: A method to identify and clone genes for proteins that interact with a protein of interest. Proc. Natl. Acad. Sci. 88: 9578-9582.

Depew, D.E. and J.C. Wang. 1975. Conformational fluctuations of the DNA double helix. Proc. Natl. Acad. Sci. 72: 42754279.

Elgin, S.C.R. 1996. Heterochromatin and gene regulation in Drosophila. Curr. Opin. Genet. Dev. 6: 193-202.

Enomoto, S. and J. Berman. 1998. Chromatin assembly factor I contributes to the mainenance, but not the re-establishment, of silencing at the yeast silent mating loci. Genes \& Dev. 12: 219-232.

Fourel, G., E. Revardel, C.E. Koering, and E. Gilson. 1999. Cohabitiation of insulators and silencing elements in yeast subtelomeric regions. $E M B O$ J. 18: 2522-2537.

Fox, C.A., S. Loo, A. Dillin, and J. Rine. 1995. The origin recognition complex has essential functions in transcriptional silencing and chromosomal replication. Genes \& Dev. 9: 911-924.

Fox, C.A., A.E. Ehrenhofer-Murray, S. Loo, and J. Rine. 1997. The origin of recognition complex, SIR1, and the S phase requirement for silencing. Science 276: 1547-1551.

Gartler, S.M. and A.D. Riggs. 1983. Mammalian X-chromosome inactivation. Ann. Rev. Genet. 17: 155-190.

Giesman, D., L. Best, and K. Tatchell. 1991. The role of RAP1 in the regulation of the MAT $\alpha$ locus. Mol. Cell. Biol. 11: 10691079 .

Hecht, A., T. Laroche, S. Strahl-Bolsinger, S.M. Gasser, and M. Grunstein. 1995. Histone H3 and H4 N-termini interact with Sir3 and Sir4 proteins: A molecular model for the formation of heterochromatin in yeast. Cell 80: 583-592.

Hecht, A., S. Strahl-Bolsinger, and M. Grunstein. 1996. Spreading of transcriptional repressor Sir3 from telomeric heterochromatin. Nature 383: 92-95.

Herskowitz, I., J. Rine, and J.N. Strathern. 1991. Mating-type determination and mating-type interconversion in Saccharomyces cerevisiae. In The molecular and cellular biology of yeast Saccharomyces: Gene expression (ed. J.R. Broach, E.W. Jones, and J.R. Pringle), pp. 583-656. Cold Spring Harbor Laboratory Press, Cold Spring Harbor, NY.

Holmes, S.G. and J.R. Broach. 1996. Silencers are required for inheritence of the repressed state in yeast. Genes \& Dev. 10: 1021-1032.

Holmes, S.G., A.B. Rose, K. Steuerle, E. Saez, S. Sayegh, Y.M. Lee, and J.R. Broach. 1997. Hyperactivation of the silencing proteins, Sir2p and Sir3p, causes chromosome loss. Genetics 145: 605-614.

Huang, D.W., L. Fanti, D.T. Pak, M.R. Botchan, S. Pimpinelli, and R. Kellum. 1998. Distinct cytoplasmic and nuclear fractions of Drosophila heterochromatin protein 1: Their phosphorylation levels and associations with origin recognition complex proteins. J. Cell Biol. 142: 307-318.

Jacobs, C.W., A.E.M. Adams, P.J. Szaniszlo, and J.R. Pringle. 1988. Functions of microtubules in the Saccharomyces cerevisiae cell cycle. J. Cell Biol. 107: 1409-1426.

Kurtz, S. and D. Shore. 1991. RAP1 protein activates and silences transcription of mating-type genes in yeast. Genes \& Dev. 5: 616-628.

Lee, J.T. and R. Jaenisch. 1997. The (epi)genetic control of mammalian X-chromosome inactivation. Curr. Opin. Genet. Dev. 7: 274-280.

Lee, S. and D.S. Gross. 1993. Conditional silencing: The HMRE mating-type silencer exerts a rapidly reversible position effect on the yeast HSP82 heat shock gene. Mol. Cell. Biol. 13: $727-738$.

Loo, S. and J. Rine. 1994. Silencers and domains of generalized repression. Science 264: 1768-1771.

_. . 1995. Silencing and heritable domains of gene expression. Annu. Rev. Cell Dev. Biol. 11: 519-548.

Lustig, A.J., C. Liu, C. Zhang, and J.P. Hanish. 1996. Tethered Sir3p nucleates silencing at telomeres and internal loci in Saccharomyces cerevisiae. Mol. Cell. Biol. 16: 2483-2495.

Lyon, M.F. 1998. X-chromosome inactivation: A repeat hypothesis. Cytogenet. Cell Genet. 80: 133-137.

Mahoney, D.J., R. Marquardt, G.-J. Shei, A.B. Rose, and J.R. Broach. 1991. Mutations in HML E silencer of Saccharomyces cerevisiae yield metastable inheritence of transcriptional repression. Genes \& Dev. 5: 605-615.

Maillet, L., C. Boscheron, M. Gotta, S. Marcand, E. Gilson, and S.M. Gasser. 1996. Evidence of silencing compartments within the yeast nucleus: A role for telomere proximity and Sir protein concentration in silencer-mediated repression. Genes \& Dev. 10: 1796-1811.

Marcand, S., S.W. Buck, P. Moretti, E. Gilson, and D. Shore. 1996. Silencing of genes at nontelomeric sites in yeast is controlled by sequestration of silencing factors at telomeres by Rap1 protein. Genes \& Dev. 10: 1297-1309.

Matsuzaki, H., R. Nakajima, J. Nishiyama, H. Araki, and Y. Oshima. 1990. Chromosome engineering in Saccharomyces cerevisiae by using a site-specific recombination system of a yeast plasmid. J. Bacteriol. 172: 610-618.

Menees, T.M. and S.B. Sandmeyer. 1994. Transposition of the yeast retrovirus-like element Ty3 is dependent on the cell cycle. Mol. Cell. Biol. 14: 8229-8240.

Miller, A.M. and K.A. Nasmyth. 1984. Role of DNA replication 
in the repression of silent mating type loci in yeast. Nature 312: 247-251.

Moazed, D. and A.D. Johnson. 1996. A deubiquinating enzyme interacts with SIR4 and regulates silencing in Saccharomyces cerevisiae. Cell 86: 667-677.

Moretti, P., K. Freeman, L. Coodly, and D. Shore. 1994. Evidence that a complex of SIR proteins interacts with the silencer and telomere-binding protein RAP1. Genes \& Dev. 8: 2257-2269.

Murphy, T.D. and G.H. Karpen. 1998. Centromeres take flight: Alpha satellite and the quest for the human centromere. Cell 93: $317-320$.

Murzina, N., A. Verreault, E. Laue., and B. Stillman. 1999. Heterochromatin dynamics in mouse cells: interaction between Chromatin Assembly Factor 1 and HP1 proteins. Mol. Cell 4: $529-540$.

Pillus, L. and J. Rine. 1989. Epigenetic inheritence of transcriptional states in Saccharomyces cerevisiae. Cell 59: 637-647.

Pryde, F.E. and E.J. Louis. 1999. Limitations of silencing at native telomeres. $E M B O$ J. 18: 2538-2550.

Renauld, H., O.M. Aparicio, P.D. Zierath, B.L. Billington, S.K. Chhablani, and D.E. Gottschling. 1993. Silent domains are assembled continuously from the telomere and are defined by promoter distance and strength, and by SIR3 dosage. Genes \& Dev. 7: 1133-1145.

Rivier, D.H., J.L. Ekena, and J. Rine. 1999. HMR-I is an origin of replication and a silencer in Saccharomyces cerevisiae. Genetics 151: 521-529.

Roman, H. 1957. Studies of gene mutation in Saccharomyces. Cold Spring Harbor Symp. Quant. Biol. 21: 175-184.

Schnell, R. and J. Rine. 1986. A position effect on the expression of a tRNA gene mediated by the SIR genes in Saccharomyces cerevisiae. Mol. Cell. Biol. 6: 494-501.

Shei, G.-J. and J.R. Broach. 1995. Yeast silencers can act as orientation-dependent gene inactivation centers that respond to environmental signals. Mol. Cell. Biol. 15: 3496-3506.

Shore, D. 1994. RAP1: A protean regulator in yeast. Trends Genet. 10: 408-412.

Singh, J. and A.J.S. Klar. 1992. Active genes in budding yeast display enhanced in vivo accessibility to foreign DNA methylases: A novel in vivo probe for chromatin structure of yeast. Genes \& Dev. 6: 186-196.

Smith, J.S., C.B. Brachmann, L. Pillus, and J.D. Boeke. 1998. Distribution of a limited Sir2 protein pool regulates the strength of yeast rDNA silencing and is modulated by Sir4p. Genetics 149: 1205-1219.

Stone, E.M. and L. Pillus. 1996. Activation of an MAP kinase cascade leads to Sir3p hyperphosphorylation and strengthens transcriptional silencing. J. Cell Biol. 135: 571-583.

Strahl-Bolsinger, S., A. Hecht, K. Luo, and M. Grunstein. 1997. Sir2 and Sir4 interactions differ in core and extended telomeric heterochromatin in yeast. Genes \& Dev. 11: 83-93.

Sussel, L., D. Vannier, and D. Shore. 1993. Epigenetic switching of transcriptional states: cis- and trans-acting factors affecting establishment of silencing at the HMR locus in Saccharomyces cerevisiae. Mol. Cell. Biol. 13: 3919-3928.

Terleth, C., C.A. van Sluis, and P. van de Putte. 1989. Differential repair of UV damage in Saccharomyces cerevisiae. Nucleic Acids Res. 17: 4433-4439.

Thompson, J.S., L.M. Johnson, and M. Grunstein. 1994. Specific repression of the yeast silent mating locus HMR by an adjacent telomere. Mol. Cell. Biol. 14: 446-455.

Triolo, T. and R. Sternglanz. 1996. Role of interactions between the origin recognition complex and SIR 1 in transcriptional silencing. Nature 381: 251-253.

Vignais, M.-L. and A. Sentenac. 1989. Asymmetric DNA bend- ing induced by the yeast multifunctional factor TUF. J. Biol. Chem. 264: 8463-8466.

Wach, A., A. Brachat, R. Pöhlmann, and P. Philippsen. 1994. New heterologous modules for classical or PCR-based gene disruptions in Saccharomyces cerevisiae. Yeast 10: 17931808.

Wallrath, L.L. and S.C.R. Elgin. 1995. Position effect variegation in Drosophila is associated with an altered chromatin structure. Genes \& Dev. 9: 1263-1277.

Weiss, K. and R.T. Simpson. 1998. High-resolution structural analysis of chromatin at specific loci: Saccharomyces cerevisiae silent mating type locus $H M L \alpha$. Mol. Cell. Biol. 18: 5392-5403.

Wiens, G.R. and P.K. Sorger. 1998. Centromeric chromatin and epigenetic effects in kinetochore assembly. Cell 93: 313316. 


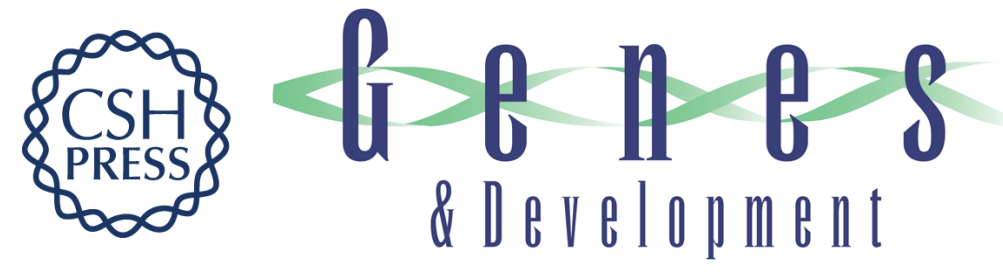

\section{Yeast heterochromatin is a dynamic structure that requires silencers continuously}

Tzu-Hao Cheng and Marc R. Gartenberg

Genes Dev. 2000, 14:

Access the most recent version at doi:10.1101/gad.14.4.452

References This article cites 69 articles, 44 of which can be accessed free at: http://genesdev.cshlp.org/content/14/4/452.full.htmI\#ref-list-1

License

Email Alerting

Receive free email alerts when new articles cite this article - sign up in the box at the top Service right corner of the article or click here.

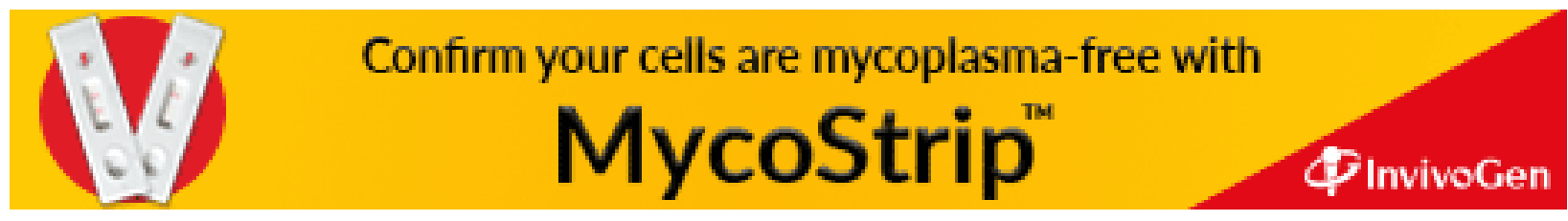

